\title{
Apples before the fall: does shape stability coincide with maturity?
}

Article

Published Version

Creative Commons: Attribution-Noncommercial-Share Alike 4.0

Open Access

Christodoulou, M. D. and Culham, A. ORCID:

https://orcid.org/0000-0002-7440-0133 (2021) Apples before the fall: does shape stability coincide with maturity?

Quantitative Plant Biology, 2. ISSN 2632-8828 doi:

https://doi.org/10.1017/qpb.2021.5 Available at

https://centaur.reading.ac.uk/97049/

It is advisable to refer to the publisher's version if you intend to cite from the work. See Guidance on citing.

To link to this article DOI: http://dx.doi.org/10.1017/qpb.2021.5

Publisher: Cambridge University Press

All outputs in CentAUR are protected by Intellectual Property Rights law, including copyright law. Copyright and IPR is retained by the creators or other copyright holders. Terms and conditions for use of this material are defined in the End User Agreement.

\section{www.reading.ac.uk/centaur}

\section{CentAUR}

Central Archive at the University of Reading 
Reading's research outputs online 
Quantitative Plant Biology

cambridge.org/qpb

\section{Original Research Article}

Cite this article: M. D. Christodoulou and A. Culham. Apples before the fall: Does shape stability coincide with maturity?. Quantitative Plant Biology, 2:e5, 1-7

https://dx.doi.org/10.1017/qpb.2021.5

Received: 3 August 2020

Revised: 26 February 2021

Accepted: 2 March 2021

Keywords:

apples; shape development; shape stability; asymmetry; geometric morphometrics; linear morphometrics.

\section{${ }^{*}$ Authors for correspondence: \\ M. D. Christodoulou, \\ E-mail: maria.christodoulou@stats.ox.ac.uk;}

and

Alastair Culham,

E-mail:a.culham@reading.ac.uk (c) The Author(s), 2021. Published by Cambridge University Press in association with The John Innes Centre. This is an Open Access article, distributed under the terms of the Creative Commons AttributionNonCommercial-ShareAlike licence (http://creativecommons.org/licenses/by-nc-sa/ 4.0/), which permits non-commercial re-use, distribution, and reproduction in any medium provided the same Creative Commons licence is included and the original work is properly cited. The written permission of Cambridge University Press must be obtained for commercial re-use.
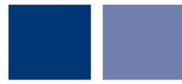

John Innes Centre

Unlocking Nature's Diversity

\section{Apples before the fall: Does shape stability coincide with maturity?}

\author{
Maria D. Christodoulou ${ }^{1,2^{*}}$ (1) and Alastair Culham ${ }^{2^{*}}$
}

${ }^{1}$ Department of Statistics, University of Oxford, Oxford, United Kingdom; ${ }^{2}$ University of Reading Herbarium, School of Biological Sciences, University of Reading, Reading, United Kingdom

\section{Introduction}

Shape development in plant organs is the product of a highly complex series of interacting molecular, biochemical and environmental pathways. At the starting point, shape development and diversity are controlled by genetics. For example, the tomato fruit shape, which has great diversity due to domestication and improvement processes, is controlled by four genes (Azzi et al., 2015). Two of these (OVATE and SUN) control fruit elongation whereas the other two (FASCIATED and LOCULE NUMBER) control locule numbers (Azzi et al., 2015). The combination of mutations in these four genes can result in the domesticated tomato shape ranging from spheroid to flat and obovoid (Monforte et al., 2014).

Aside from genetic effects, shape development is also impacted by phenotypic plasticity. Phenotypic plasticity is defined as the morphological, phenotypical or behavioural changes that are caused as a direct response to environmental stimuli (Price et al., 2003). There are multiple examples of shape change as an environmental response in both plants and animals. In a study of Datura wrightii hort. ex Regel floral shape, phenotypic plasticity was demonstrated as a response to watering regime (Elle \& Hare, 2002). In a common-garden experiment, plants that were watered twice a week had consistently longer corollas compared with plants that received only rainfall (Elle \& Hare, 2002). In a range of ecotypes of Arabidopsis thaliana (L.) Heynh., leaf shape is reportedly altered when light levels are reduced, presenting smaller leaves and longer petioles (Tsukaya, 2006).

Even though phenotypic plasticity is well recorded, there are processes counteracting the environmental impact on the phenotype, specifically two buffering processes that promote phenotypic stability have been described (Willmore et al., 2005). Canalisation is described as the ability of an organism to buffer against both environmental and genetic variation in order to maintain phenotypic stability (Breuker et al., 2006). On the other hand, developmental stability is the ability of an organism to buffer against random variation in order to maintain phenotypic stability (Willmore et al., 2005). The two mechanisms, although clearly defined, are difficult to isolate in developmental work. In a study of Drosophila melanogaster Meigen wing shape and size, Breuker et al. (2006) demonstrated the possibility that the two buffering pathways 
were fundamentally parts of a single process. Examples of developmental buffering have been described in both animals and plants. Tsukaya (2003) reported that in A. thaliana, manipulation of cell size and numbers in developing leaves was to a certain degree buffered in order to produce a stable phenotype. Manipulation of cell division rates in Pelargonium leaves demonstrated a mechanism where the faster dividing cells compensated for the slower dividing ones, resulting in a consistent shape (Day \& Lawrence, 2000).

Shape is a major morphological descriptor of an organism; as such shape stability and by extension morphological stability, become fundamental biological concepts. This is even more so for cultivars which are distinguished by multiple but often very minor morphological differences. A key element of cultivar description is variation in size and shape. As opposed to species, cultivars have a very clear definition, a fact primarily due to the man-made nature of cultivars. Cultivars are described based on the selection of particular characters and these characters are required to be distinct, uniform and stable (Brickell et al., 2009). If a cultivar, therefore, is described based on particular morphological characters (which could include shape) then there is a requirement for stability of these characters. Differences in commercial value of cultivars within a species can be substantial which gives rise to the need for confident identification of individual cultivars (Christodoulou et al., 2018; Christodoulou et al., 2020).

Closer to the focus of this work, there have been a number of studies on the effect of environmental conditions on apple fruit growth and development. McKenzie (1971), in a general survey of apple fruit shape in New Zealand, recorded differences in shape between apples of the same cultivar grown in the north and south of New Zealand. In a study of light quality effect on 'Golden Delicious' apples, Noè and Eccher (1996) established that light levels and quality can affect both fruit shape and russeting. On the other hand, when Tromp (1990) studied the environmental effects on fruit shape of 'Cox's Orange Pippin' using controlled environment rooms he found no significant differences. What makes this finding particularly interesting is that the environment was controlled for all the trees from anthesis onwards. It is therefore possible that the phenotypic plasticity recorded by McKenzie (1971) was due to environmental differences prior to anthesis. This is of interest because it has been recorded that the effect of the OVATE gene in tomatoes is established prior to anthesis (Monforte et al., 2014). Although it is not argued that the apple will have the same mechanisms as the tomato, both are climacteric domesticated fruit therefore similarities are possible. Since, the first whole genome iteration for apples was released (Velasco et al., 2010), characters such as ripening, pedigree origins, and leaf morphology have been studied, making the genetic basis of fruit shape an expected future topic of study by horticultural geneticists (Migicovsky et al., 2018; Muranty et al., 2020; Peace et al., 2019).

Apple fruit are therefore seen to be subject to variation caused by environmental factors as well as due to genetic differences. Despite this variation, there appears to be sufficient buffering to ensure that apple fruit can be identified to cultivar by appearance with a reasonable degree of accuracy ( $>77 \%$, Christodoulou et al., 2018) which is further evidenced by the fact that the widely sold apple cultivars seen in supermarkets look much the same throughout the year whether they are sourced from UK, South Africa, Spain, Chile or New Zealand. Supermarket fruit are subject to quality selection and so are more homogeneous in morphology than random samples from an orchard. If environment has a greater influence than genotype such fruit homogeneity would not be achievable by supermarkets.
Traditionally, apple fruit shape was described by comparison with a standard geometric object (Bultitude, 1983). Examples of the possible shape categories included: oblong, conical or round (Clark \& Cleal, 2005). This practice, which is still common in both identification keys and collection curation tools, aimed to summarise the extensive variety of shapes by grouping using a collection of predefined geometrical shapes (Sanders, 2010). In order to quantify shape, Westwood (1962) used the ratio between length and diameter (L/D) of the fruit. Using the $\mathrm{L} / \mathrm{D}$ ratio as a proxy for shape, Westwood (1962) suggested that shape for apple cultivars stabilised between Day 60 and Day 100 from anthesis. The use of the $\mathrm{L} / \mathrm{D}$ ratio has both benefits and limitations. By using measurements in two perpendicular axes, it facilitated the description of the overall shape in two dimensions. It also permitted the comparison between shapes, with ratios below 1 indicating a fruit that is wider than long and vice versa.

The description of ratios is easy to communicate, and intuitive but there are analytical concerns which arise from such use. First, a ratio of two normally distributed variables is not necessarily normally distributed (Atchley et al., 1976). This means that a ratio may not be suitable for analysis using parametric techniques, which assume normality. Second, ratio use is inherently paradoxical: if the variables in the ratio are unrelated, the ratio calculation creates a relationship (Curran-Everett, 2013). If, on the other hand, the two variables are related, the ratio calculation will only successfully demonstrate this relationship if it is linear and crosses the origin (Jackson et al., 1990). Third, ratio use can give rise to spurious correlations if the two variables used are both affected by a common confounding factor (Tu et al., 2010). These three issues can be avoided, while still using length and diameter measurements as shape proxies, by performing an analysis of covariance (Tu et al., 2010).

In this work, we aim to investigate if and when fruit shape stabilises for apple cultivars, whether the timings of this are cultivardependent, and if shape stability timings as described through linear morphometrics differ from those described through geometric morphometrics. These findings will have immediate commercial application to the marketing of apple cultivars harvested prior to full physiological maturity.

\section{Materials and methods}

\subsection{Sample collection}

Twelve apple cultivars were sampled throughout the 2013 growing season at regular intervals, beginning at 2 weeks from flowering (anthesis) and ending when the orchard's pickers deemed the fruit ripe for eating. Ten fruit per cultivar were collected at every sampling point with the exception of the last harvest were 20 fruit were collected. Anthesis for the orchard in 2013 occurred on June 10, 2013. All fruit were collected from the National Fruit Collection, in Brogdale, Kent, UK. In 2014, 6 of the 12 cultivars were randomly selected to be resampled. Anthesis for 2014 occurred on 1May 15, 2014. A full list of cultivars and their sampling times are available in the Supplementary Materials.

\subsection{Morphometric data collection}

Measurements of length and diameter (linear morphometrics), and geometric morphometrics for each sample were collected as described in Christodoulou et al. (2018). Geometric morphometrics were only collected for the 2013 season. The 


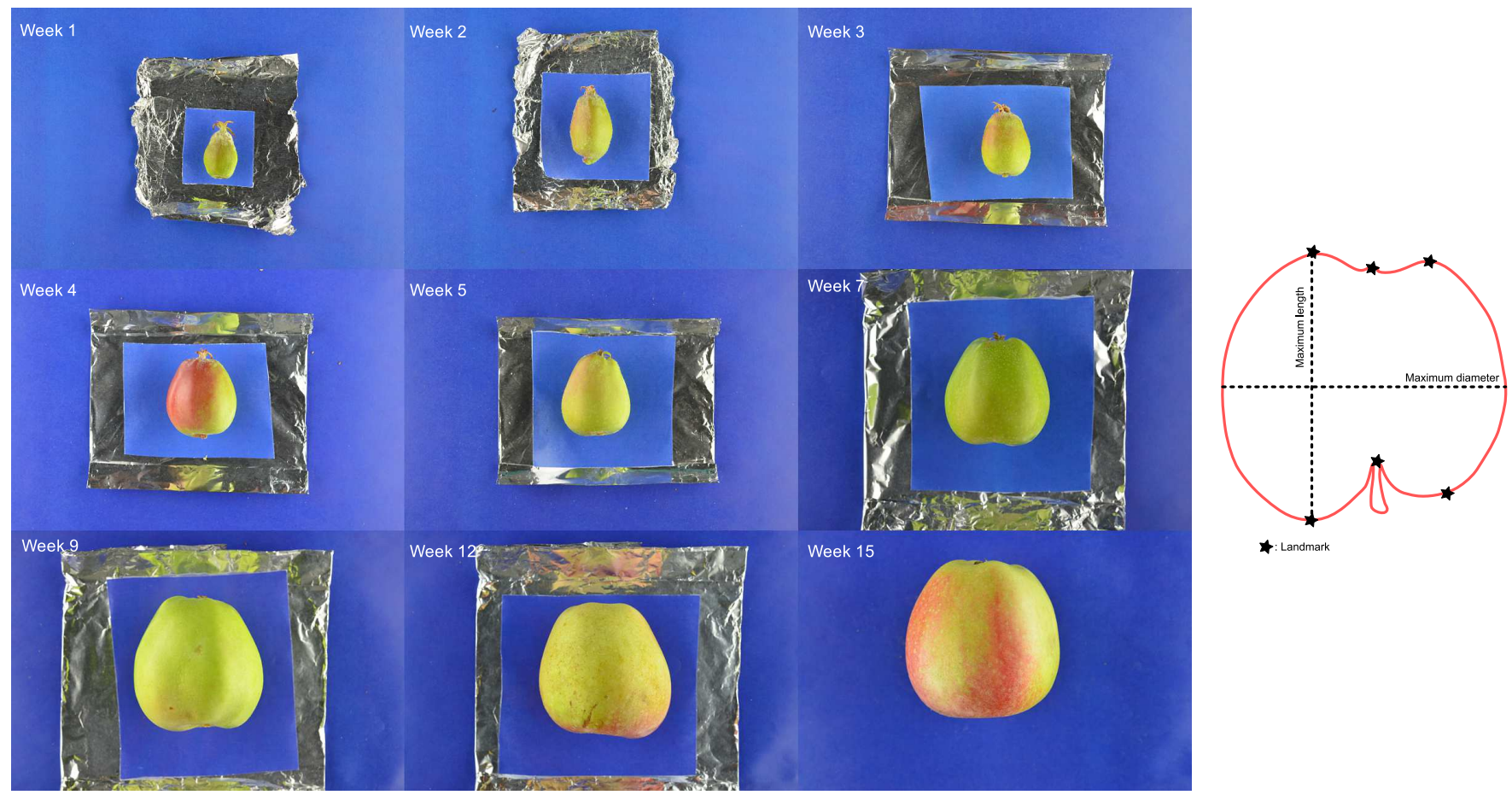

Fig. 1. Example images for Adam's Pearmain, digitised landmarks and linear morphometrics used on the sampled fruit. Six landmarks were selected per sample: two on the crown apices, one on the calyx, one on the pedicel attachment point and two on the shoulder apices. Maximum length and diameter were measured using precision callipers.

chosen landmarks and linear morphometrics are summarised in Figure 1.

\subsection{Shape development analysis}

Analysis of Covariance (ANCOVA) was performed for each cultivar to examine how sampling week interacts with the correlation between length and diameter. To detect stability of shape for two sampling weeks, their slopes and intercepts had to be found not to be significantly different.

For the geometric morphometrics, regression for allometric effect was performed on MorphoJ (Klingenberg, 2011) and if found to be significant, analysis proceeded using the regressed dataset (Klingenberg \& Marugán-Lobón, 2013; Openshaw \& Keogh, 2014). If not, the dataset prior to allometric correction was employed. The allometric analysis step was performed to establish whether the effect of size was significant to the variation between samples. If the results were found to be significant, the dataset was corrected to exclude the variation that was explained by size. After removing the variation that was explained by size, the remaining variation between samples was attributed to shape differences. If the allometric analysis indicated that the effect of size was not significant for the variation between samples, the correction was not necessary and the data prior to regression were used. A canonical variates analysis (CVA) was performed using harvest times as the classifier followed by a permutation test (10,000 permutations). The $p$-values of the Mahalanobis distances of the permutation test were used to establish shape differences between weeks (Zelditch et al., 2004).

\subsection{Asymmetry analysis}

To study whether differences in shape stability between cultivars were linked to fruit asymmetry, Procrustes ANOVAs were per- formed on the selected landmarks for the final harvest images for each cultivar (Klingenberg et al., 2002). In each case, the axis of asymmetry was selected to pass through the calyx and pedicel landmarks. The two halves were compared with each other to establish whether there was statistical evidence of systematic asymmetry.

\section{Results}

\subsection{Linear morphometrics}

Only 3 of the 12 cultivars stabilised prior to the last harvest. These were 'Adam's Pearmain' (stable from Week 12 until Week 15), 'Beacon' (stable from Week 9 until Week 12) and 'Wheeler's Russet' (stable from Week 12 until Week 17 in 2013, and Week 12 until 18 in 2014). All other cultivars demonstrated significant differences in the intercepts for the final sampling weeks. All code and model results are available as an R project, in the Supplementary Materials.

\subsection{Geometric morphometrics}

When studied for allometry, 11 out of 12 cultivars demonstrated a significant allometric effect. The only cultivar that did not present a significant allometric effect was 'Beacon', and in this case, the original data were not corrected for allometry. The remaining 11 cultivars were all corrected for allometry prior to further analysis. The percentage of variation explained by size as well as the associated $p$-values are summarised in Table S1, in the Supplementary Materials.

Each cultivar was studied using a CVA with harvesting times as the grouping factor. This was followed by a permutations test that compared the differences between all possible harvesting time combinations. The $p$-values from the 10,000 permutations test on the Mahalanobis distances were recorded for each harvest comparison. As the focus of this analysis was on the stability of shape 


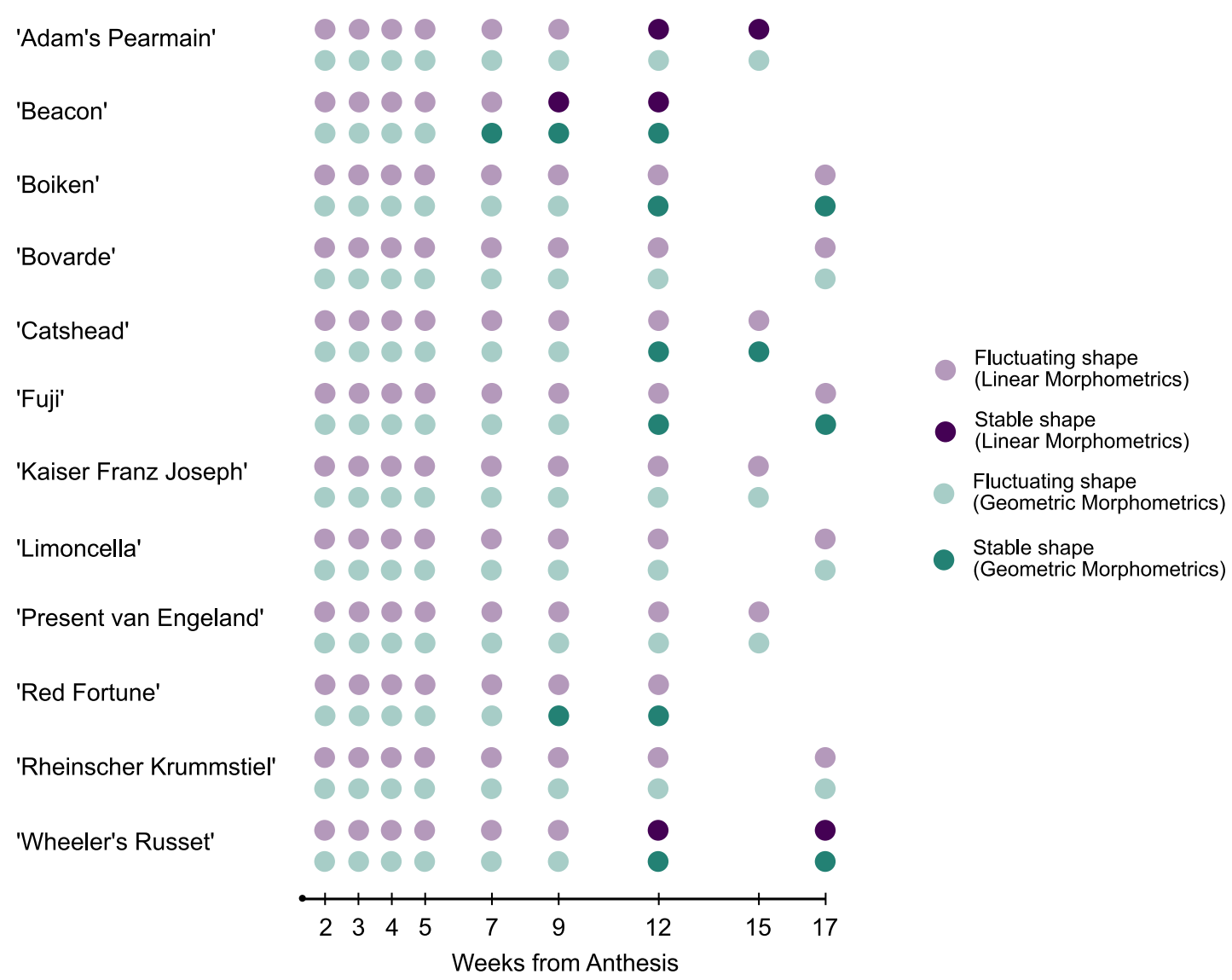

Fig. 2. Shape stability status per Week/Cultivar for the 2013 growing season. Stability detection through linear morphometrics indicated in purple (pale for fluctuating shape and dark purple for stable shape), and geometric morphometrics in green (pale for fluctuating shape and dark green for stable shape). Asymmetric cultivars indicated with an asterisk after the cultivar name. Weeks are measured from flowering (anthesis). The two early season cultivars ('Beacon' and 'Red Fortune') are placed on the top of the chart. All other cultivars are main season cultivars.

between at least penultimate and ultimate harvests, only those comparison results are summarised in Table 1 below. Results from

Table 1. Summary of canonical variates analyses results between penultimate and ultimate harvests for the 12 studied cultivars

\begin{tabular}{|c|c|c|c|}
\hline Cultivar & $\begin{array}{c}\text { Penultimate } \\
\text { harvect } \\
\text { week }\end{array}$ & $\begin{array}{c}\text { Final } \\
\text { harvect } \\
\text { week }\end{array}$ & $p$-value \\
\hline 'Adam's Pearmain' & Week 12 & Week 15 & $0.0002(* * *)$ \\
\hline ‘Beacon’ & Week 9 & Week 12 & 0.0864 (NS) \\
\hline ‘Boiken’ & Week 12 & Week 17 & 0.2119 (NS) \\
\hline 'Bovarde' & Week 12 & Week 17 & $0.0069\left(^{* *}\right)$ \\
\hline ‘Catshead' & Week 12 & Week 15 & 0.062 (NS) \\
\hline ‘Fuji' & Week 12 & Week 17 & 0.2973 (NS) \\
\hline ‘Kaiser Franz Joseph’ & Week 12 & Week 15 & $0.0001(* * *)$ \\
\hline ‘Limoncella’ & Week 12 & Week 17 & $0.0057\left(^{* *}\right)$ \\
\hline ‘Present van Engeland’ & Week 12 & Week 15 & $0.0032\left(^{* *}\right)$ \\
\hline 'Red Fortune’ & Week 9 & Week 12 & 0.0633 (NS) \\
\hline ‘Rheinischer Krummstiel' & Week 12 & Week 17 & $0.0093\left(^{* *}\right)$ \\
\hline ‘Wheeler's Russet' & Week 12 & Week 17 & 0.1514 (NS) \\
\hline
\end{tabular}

The $p$-values from the 10,000 permutations tests on the Mahalanobis distances are reported for each comparison (star significance in brackets). all other harvest comparisons can be found in the Supplementary Materials.

Shape stability for 2013, using both linear and geometric morphometrics, is summarised in Figure 2. Shape stability for the six cultivars repeated in 2014, using linear morphometrics, is summarised in Figure 3.

The impact of the linear versus geometric morphometrics used to describe potential fruit shape stability can be observed in Figure 1. Whether stability happens and when it occurs matches on half of the tested cultivars for the two techniques. Five out of these six cultivars do not demonstrate shape stability as defined here ('Bovarde', 'Kaiser Franz Joseph', 'Limoncella', 'Present van Engeland' and 'Rheinischer Krummstiel'). Shape stability using each method occurs at the same time only on 'Wheeler's Russet'. Cultivar 'Beacon' demonstrates shape stability for each of these methods but the point in time at which this is reached differs. For four of the remaining cultivars, stability is detected through geometric and not through linear morphometrics ('Boiken', 'Catshead', 'Fuji' and 'Red Fortune'). Shape stability was detected through linear morphometrics and not geometric only for 'Adam's Pearmain'.

Results from the symmetry analysis are in Table 2. Of the 12 cultivars, 5 were asymmetric and seven symmetric.

Summary results for stability detection and presence of symmetry are in Table S2 of the Supplementary Materials. Overall, presence of stability in symmetric cultivars was detected only through geometric morphometrics. For asymmetric fruit, both methods perform similarly. 


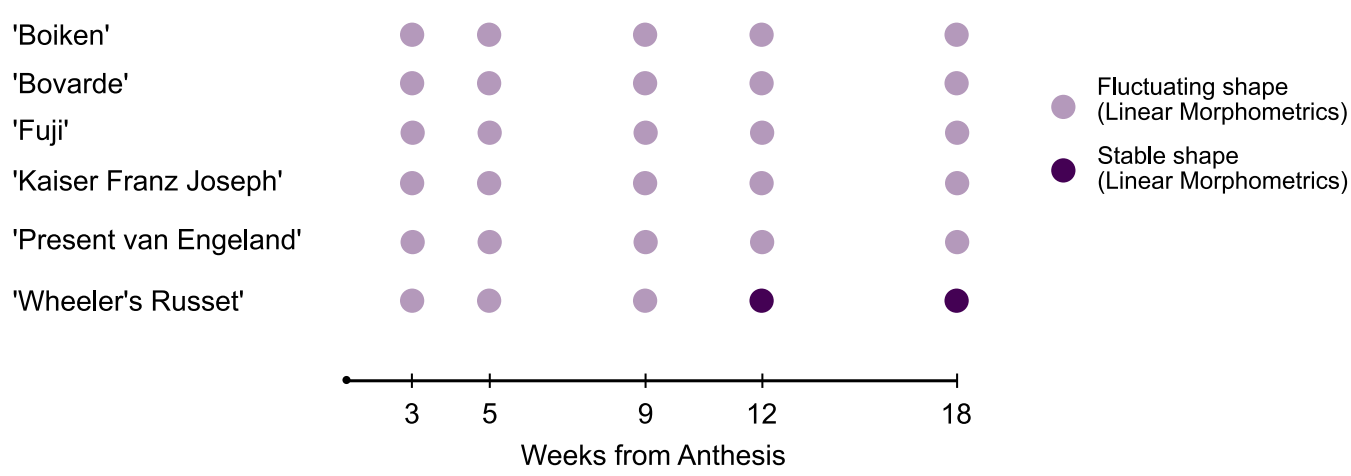

Fig. 3. Shape stability status per Week/Cultivar for the 2014 growing season. Stability detection for that year was only conducted through linear morphometrics (pale purple for fluctuating shape and dark purple for stable shape). Asymmetric cultivars indicated with an asterisk after the cultivar name. Weeks are measured from flowering (anthesis). All cultivars are main season cultivars.

Table 2. Symmetry analysis results for harvest week samples

\begin{tabular}{|c|c|c|}
\hline Cultivar & $\begin{array}{c}\text { Final } \\
\text { harvest } \\
\text { week }\end{array}$ & $\begin{array}{c}p \text {-value } \\
\text { for } \\
\text { symmetry }\end{array}$ \\
\hline 'Adam's Pearmain' & Week 15 & $<0.0001(* * *)$ \\
\hline 'Beacon' & Week 12 & $<0.0001\left({ }^{* * *}\right)$ \\
\hline ‘Boiken’ & Week 17 & 0.0866 (NS) \\
\hline 'Bovarde' & Week 17 & 0.0964 (NS) \\
\hline 'Catshead' & Week 15 & 0.5275 (NS) \\
\hline ‘Fuji’ & Week 17 & 0.2627 (NS) \\
\hline ‘Kaiser Franz Joseph’ & Week 15 & 0.2668 (NS) \\
\hline 'Limoncella' & Week 17 & 0.0528 (NS) \\
\hline 'Present van Engeland' & Week 15 & $<0.0001(* * *)$ \\
\hline 'Red Fortune' & Week 12 & $0.0017\left({ }^{* *}\right)$ \\
\hline 'Rheinischer Krummstiel' & Week 17 & 0.0903 (NS) \\
\hline 'Wheeler's Russet' & Week 17 & $0.0154\left(^{*}\right)$ \\
\hline
\end{tabular}

\section{Discussion}

Our results highlight two clear outcomes:

1. The method used to quantify shape impacts on our ability to describe and detect shape stability.

2. Shape stability, when it happens, occurs late in the season and is cultivar dependent.

The earliest time when stability is first detected in any cultivar is Week 7 ('Beacon', 49 days from anthesis), and the latest time of first detection is during Week 12 (e.g. 'Catshead', 84 days from anthesis). In total, 7 of the 12 cultivars tested reach shape stability by at least one measure during this period. The remaining five cultivars do not achieve a stable shape by the time they are harvested based on our two approaches to measurement. This could be an accurate description of absence of stability or a consistent failure of either method to detect it. Comparing these findings with Westwood's (1962) original observations of shape stability occurring between Day 60 (Week 9) and Day 100 (Week 14) from anthesis, suggests that for the majority of cultivars we are detecting similar trends. Whether these patterns are representative of shape stability is more a question of the reliability of our definition of the phenomenon than the presence of significant differences between weeks.

We define shape stability under linear morphometrics by testing whether the regression between length and diameter for the last harvest is significantly different to the regression of the preceding week. This therefore depends on whether we consider length and diameter in combination to be sufficient shape descriptors. For the geometric morphometrics, the method in combination with a permutation test, uses the position of the six landmarks selected to detect whether there are significant differences between weeks. Again, the success of the method relies on whether we believe the six landmarks selected to be sufficient shape descriptors. Both linear and geometric morphometrics, as described here, were used as underlying data for a machine learning classification method aiming to identify apple cultivars, which achieved $77.8 \%$ accuracy on an unclassified test set (Christodoulou et al., 2018) As such, we believe that the shape descriptions used for both methods are reflective of the cultivar shape, therefore their use for evaluation of shape stability is justified. Shape stability is an important commercial factor in fruit sales because customers expect uniform fruit at the point of purchase.

Linear morphometrics rely on individual measurements, geometric morphometrics combine positions of multiple landmarks. Comparison of findings between the two techniques illustrates this fundamental difference. In the case of shape stability this would be illustrated by geometric morphometrics detecting stability more readily than linear ones. This is the case for five cultivars in this study. Shape stability for symmetric apples was detected only using geometric morphometrics, whilst shape stability for asymmetric apples was detected in three out five cultivars by geometric morphometrics and two out of five by linear morphometrics. This means that linear morphometrics is not an effective approach to detect shape stability in symmetric apples and that geometric morphometrics is effective for both.

Some cultivars (such as 'Beacon' and 'Wheeler's Russet') stabilised in shape prior to the final harvest week, while others did not appear to do so (e.g. 'Bovarde' and 'Rheinischer Krummstiel'). This suggests that shape stability is cultivar dependent. These findings are congruent with the 2014 follow-up collection for limited samples. In terms of growing practices, the National Fruit Collection followed identical growing protocols between the 2 years. No differences in pest presence or management were recorded between the 2 years and pollination levels were similar. The observable difference in the 2 years is weather. Specifically, 2013 was cooler 
and drier than 2014. As this resulted in no differences in which cultivar stabilised prior to harvest, we can hypothesise that stability of shape is not easily perturbed by weather, We find that to be an unexpected finding and therefore this hypothesis would have to be specifically tested, as it contradicted previous work. For example, McKenzie (1971) demonstrated that weather conditions can substantially affect shape in 'Delicious' apples grown in New Zealand. Studies on 'Cox's Orange Pippin' suggested that cooler spring temperatures - such as the ones observed in 2013 - were associated with higher fruit yield by improving seed-set (Jackson et al., 1983; Jackson \& Hamer, 1980). The fact that seed-set was affected by pre-anthesis temperatures is directly relevant to fruit shape as Drazeta et al. (2004) demonstrated increased asymmetry on 'Granny Smith' apples due to seed-set success and seed weight. These led us to expect differences in fruit shape stability between the 2 years which we did not observe. The levels of 'June drop' (self-thinning immature fruit drop) were similar in the 2 years.

The observed shape stability differences between cultivars could be due to differences in developmental buffering. If the developmental stability or canalisation abilities differed between cultivars, then some would be less prone to reaching a stable shape than others. It is therefore possible that the environmental conditions under which all the cultivars were grown, affected the developmental buffering mechanisms to different degrees, resulting in shape stability for some cultivars and none for others. Measuring developmental buffering in morphometric studies often relies on the concept of fluctuating asymmetry (FA) (Klingenberg et al., 2002). By measuring the differences between two structures in the same organism which are controlled by the same genetic mechanisms the stability of developmental process can be measured (Willmore et al., 2005). For example, if the asymmetry between the right wing and the left wing of a Drosophila is measured then the success of the developmental buffering for that Drosophila can be quantified. Since both wings were developed under exactly the same genetic, epigenetic and environmental conditions any differences between the two sides should be down to the buffering success of the organisms as a whole. Using FA as a measure of developmental buffering however may not be appropriate for apple fruit development. This is because the assumption of environmental stability between the two sides of the fruit may not hold. As apple fruit grow in clusters, the exposure of the individual fruit to the external environment varies. These different localised environmental conditions confound the developmental buffering. To measure developmental buffering for apples, we believe that a study needs to be conducted under strictly controlled environmental conditions, otherwise the environmental noise is likely to overcome the developmental signal.

We have previously shown that apples do not stop growing until they are harvested (Christodoulou \& Culham, 2020). The mix of cultivars that show shape stability before harvest and those that do not, may be indicative of growth and development of individual fruit slowing sufficiently resulting in our metrics not detecting subtle changes as the fruit approach physiological maturity. The evidence that changes become increasingly subtle as maturity is reached is congruent with the fact that apple cultivars can be recognised from their distinct shapes and sizes at harvest. Contrasting our findings with earlier work on authentication of apples using harvest shape (Christodoulou et al., 2018), we note that there is no correlation in the success in identification and the cultivars that stabilised prior to harvest.

\section{Conclusions}

In this work, we aimed to establish if and when fruit shape of apple cultivars stabilises prior to harvesting, and whether the findings are impacted by the method used - contrasting linear and geometric morphometrics. We established that the consistency of our findings is method-dependent, with geometric morphometrics detecting stability more readily than linear morphometrics. Some cultivars never reached stability prior to harvest. Whether or not the shape stabilised, apple cultivars are geometrically different from each other such that they can usually be identified by their shape. Remarkably, apple cultivars can be identified with a high degree of success despite continued growth and sometimes continued shape change up until the point of harvest.

\section{Acknowledgements}

We thank Prof Nick Battey, Dr Matthew Ordidge, and the National Fruit Collection, Brogdale, Kent, for access to samples and assistance with sampling.

Financial support. This work was supported by BBSRC: 1132848, https://www.bbsrc.ac.uk/. The funders had no role in study design, data collection and analysis, decision to publish, or preparation of the manuscript.

Conflict of interest. The authors declare no conflicts of interest.

Authorship contributions. M.D.C. was responsible for data curation, formal analysis, methodology, validation, writing of manuscript. A.C. was responsible for conceptualisation, funding acquisition, project administration, supervision and writing of manuscript.

Data availability statement. All data and code have been submitted as supplementary materials.

Supplementary Materials. To view supplementary material for this article, please visit http://dx.doi.org/10.1017/qpb.2021.5.

\section{References}

Atchley, W. R., Gaskins, C. T., \& Anderson, D. (1976). Statistical properties of ratios. I. Empirical results. Systematic Zoology, 25, 137-148. https://doi.org/10.2307/2412740

Azzi, L., Deluche, C., Gevaudant, F., Frangne, N., Delmas, F., Hernould, M., \& Chevalier, C. (2015). Fruit growth-related genes in tomato. Journal of Experimental Botany, 66, 1075-1086. https://doi.org/10.1093/jxb/eru527

Breuker, C. J., Patterson, J. S., \& Klingenberg, C. P. (2006). A single basis for developmental buffering of Drosophila wing shape. PLoS One, 1, 1-7. https://doi.org/10.1371/journal.pone.0000007

Brickell, C. D., Alexander, C., David, J. C., Hetterscheid, W. L. A., Leslie, A. C., Malecot, V., Jin, X., \& Cubey, J. J. (2009). International code of nomenclature for cultivated plants (8th ed.). International Society for Horticultural Science.

Bultitude, J. (1983). Apples: a guide to the identification of international varieties. Macmillan Press London.

Christodoulou, M. D., Battey, N. H., \& Culham, A. (2018). Can you make morphometrics work when you know the right answer? Pick and mix approaches for apple identification. PLoS One, 13, e0205357. https://doi.org/ 10.1371/journal.pone.0205357

Christodoulou, M. D., Clark, J. Y., \& Culham, A. (2020). The Cinderella discipline: morphometrics and their use in botanical classification. Botanical Journal of the Linnean Society, 194, 385-396. https://doi. org/10.1093/botlinnean/boaa055

Christodoulou, M. D, \& Culham, A. (2020). When do apples stop growing, and why does it matter? BioRxiv, 1-17. https://doi.org/ $10.1101 / 2020.06 .25 .170910$ 
Clark, S., \& Cleal, Q. (2005). A manual key for the identification of apples based on descriptions in Bultitude (1983) (Vol. 3). National Fruit Collection, Brogdale, UK.

Curran-Everett, D. (2013). Explorations in statistics: The analysis of ratios and normalized data. Advances in Physiology Education, 37, 213-219. https://doi.org/10.1152/advan.00053.2013

Day, S. J., \& Lawrence, P. A. (2000). Measuring dimensions: The regulation of size and shape. Development, 127, 2977-2987.

Drazeta, L., Lang, A., Hall, A. J., Volz, R. K., \& Jameson, P. E. (2004). Modelling the influence of seed set on fruit shape in apple. Journal of Horticultural Science \& Biotechnology, 79, 241-245.

Elle, E., \& Hare, J. D. (2002). Environmentally induced variation in floral traits affects the mating system in Datura wrightii. Functional Ecology, 16, 79-88. https://doi.org/10.1046/j.0269-8463.2001.00599.x

Jackson, D. A., Harvey, H. H., \& Somers, K. M. (1990). Ratios in aquatic sciences: Statistical shortcomings with mean depth and the morphoedaphic index. Canadian Journal of Fisheries and Aquatic Sciences, 47, 1788-1795. https://doi.org/10.1139/f90-203

Jackson, J. E., \& Hamer, P. J. C. (1980). The causes of year-to-year variation in the average yield of Cox's Orange Pippin apple in England. Journal of Horticultural Science, 55, 149-156.

Jackson, J. E., Hamer, P. J. C., \& Wickenden, M. F. (1983). Effects of early spring temperatures on the set of fruits of Cox's Orange Pippin apple and year to year variation in its yields. Acta Horticulturae, 139 75-82.

Klingenberg, C. (2011). MorphoJ: An integrated software package for geometric morphometrics. Molecular Ecology Resources, 11, 353-357. https://doi.org/10.1111/j.1755-0998.2010.02924.x

Klingenberg, C. P., Barluenga, M., \& Meyer, A. (2002). Shape analysis of symmetric structures: Quantifying variation among individuals and asymmetry. Evolution, 56, 1909-1920. https://doi.org/10.1554/0014-3820(2002)056

Klingenberg, C. P., \& Marugán-Lobón, J. (2013). Evolutionary covariation in geometric morphometric data: Analyzing integration, modularity, and allometry in a phylogenetic context. Systematic Biology, 62, 591-610. https://doi.org/10.1093/sysbio/syt025

McKenzie, D. W. (1971). A survey of shape variation in some New Zealand apples. New Zealand Journal of Agricultural Research, 14, 491-498. https://doi.org/10.1080/00288233.1971.10427111

Migicovsky, Z., Li, M., Chitwood, D. H., \& Myles, S. (2018). Morphometrics reveals complex and heritable apple leaf shapes. Frontiers in Plant Science, $\mathbf{8}$, 1-14. https://doi.org/10.3389/fpls.2017.02185

Monforte, A. J., Diaz, A., Cano-Delgado, A., \& van der Knaap, E. (2014). The genetic basis of fruit morphology in horticultural crops: Lessons from tomato and melon. Journal of Experimental Botany, 65, 4625-4637. https://doi.org/10.1093/jxb/eru017

Muranty, H., Denancé, C., Feugey, L., Crépin, J. L., Barbier, Y., Tartarini, S., Ordidge, M., Troggio, M., Lateur, M., Nybom, H., Paprstein, F., Laurens, F., \& Durel, C. E. (2020). Using whole-genome SNP data to reconstruct a large multi-generation pedigree in apple germplasm. BMC Plant Biology, 20, 1-18. https://doi.org/10.1186/s12870-019-2171-6

Noè, N., \& Eccher, T. (1996). 'Golden Delicious' apple fruit shape and russeting are affected by light conditions. Scientia Horticulturae, 65, 209-213. https://doi.org/10.1016/0304-4238(95)00850-0

Openshaw, G. H., \& Keogh, J. S. (2014). Head shape evolution in monitor lizards (Varanus): Interactions between extreme size disparity, phylogeny and ecology. Journal of Evolutionary Biology, 27, 363-373. https://doi.org/10.1111/jeb.12299

Peace, C. P., Bianco, L., Troggio, M., van de Weg, E., Howard, N. P., Cornille, A., Durel, C. E., Myles, S., Migicovsky, Z., Schaffer, R. J., Costes, E., Fazio, G., Yamane, H., van Nocker, S., Gottschalk, C., Costa, F., Chagné, D., Zhang, X., Patocchi, A., ... Vanderzande, S. (2019). Apple whole genome sequences: Recent advances and new prospects. Horticulture Research, 6, 59. https://doi.org/10.1038/s41438-019-0141-7

Price, T. D., Qvarnström, A., \& Irwin, D. E. (2003). The role of phenotypic plasticity in driving genetic evolution. Proceedings of the Royal Society B-Biological Sciences, 270, 1433-1440. https://doi.org/10.1098/rspb.2003. 2372

Sanders, R. (2010). The Apple Book (1st ed.). Frances Lincoln Limited Publishers.

Tromp, J. (1990). Fruit shape in apple under various controlled environment conditions. Scientia Horticulturae, 43, 109-115. https://doi.org/ 10.1016/0304-4238(90)90042-D

Tsukaya, H. (2003). Organ shape and size: A lesson from studies of leaf morphogenesis. Current Opinion in Plant Biology, 6, 57-62. https://doi.org/ $10.1016 /$ S1369526602000055

Tsukaya, H. (2006). Mechanism of leaf-shape determination. Annual Review of Plant Biology, 57, 477-496. https://doi.org/10.1146/annurev. arplant.57.032905.105320

Tu, Y. K., Law, G. R., Ellison, G. T. H., \& Gilthorpe, M. S. (2010). Ratio index variables or ANCOVA? Fisher's cats revisited. Pharmaceutical Statistics, 9, 77-83. https://doi.org/10.1002/pst.377

Velasco, R., Zharkikh, A., Affourtit, J., Dhingra, A., Cestaro, A., Kalyanaraman, A., Fontana, P., Bhatnagar, S. K., Troggio, M., Pruss, D., Salvi, S., Pindo, M., Baldi, P., Castelletti, S., Cavaiuolo, M., Coppola, G., Costa, F., Cova, V., Dal Ri, A., ... Viola, R. (2010). The genome of the domesticated apple (Malus $\times$ domestica Borkh.). Nature Genetics, 42, 833-839. https://doi.org/10.1038/ng.654

Westwood, M. N. (1962). Seasonal changes in specific gravity and shape of apple, pear and peach fruits. Proceedings of the American Society for Horticultural Science, 80, 90-96.

Willmore, K. E., Klingenberg, C. P., \& Hallgrimsson, B. (2005). The relationship between fluctuating asymmetry and environmental variance in Rhesus Macaque skulls. Evolution, 59, 898-909.

Zelditch, M. L., Swiderski, D. L., Sheets, H. D., \& Fink, W. L. (2004). Geometric morphometrics for biologists. In Elsevier (Vol. 59, 2nd ed.). Elsevier Academic Press. https://doi.org/10.1016/B978-0-12-386903-6.00001-0 